\title{
Decomposition Analysis on Influence Factors of Direct Household Energy-related Carbon Emission in Guangdong Province-Based on Extended Kaya Identity
}

\author{
Wenxiu Wang ${ }^{1}$, Daiqing Zhao ${ }^{1}$, and Wenjun Wang ${ }^{1, *}$ \\ ${ }^{1}$ Guangzhou Institute of Energy Conversion, Chinese Academy of Sciences, No.2,Nengyuan Rd.,Wushan,Tianhe District,Guangzhou \\ 510640, China
}

\begin{abstract}
The decomposition quantitative model of household energy-related carbon emission in Guangdong is established based on the extended Kaya identity with the Logarithmic Mean Divisia Index (LMDI) method. Influence factors of household energy-related carbon emission are decomposed into five factors. Main results show that total household energy-related carbon emissions in Guangdong province show increase trend from 1995 to 2016. Electric power consumption is the biggest source of household energy-related carbon emission. The results of decomposition show that population size is the first promote factor to household energy-related carbon emission in 1996-2004. Energy use level become the first promote factor in 2005-2016. Carbon emission coefficient show reduction effect, which is the first inhibit factor to energy-related carbon emission. Finally, two effective means to reduce household carbon emissions are given to Guangdong province.
\end{abstract}

\section{Introduction}

Consumption is one of the three main driving forces (exports, investment and consumption) of economic development ${ }^{[1]}$. Residents' consumption is an important part of consumption, which together with government consumption and investment and net exports constitute the entire national economy. With the energy issue and global warming becoming the hot topic of international society, the domestic and foreign scholars carried out most researches on the field of production to make scientific and effective carbon emission reduction measures in production department. But many researches show that energy consumption and carbon emissions in household of some developed countries increase year by year in recent years, even surpassed energy consumption and carbon emissions in production department ${ }^{[2-4]}$. Energy - related carbon emissions from households are becoming increasingly important.

China is in the crucial stage of residents' consumption growth and consumption upgrade, with the high-speed development of social economy and the advancement of urbanization, energy consumption and carbon emissions caused by resident's consumption will increase year by year. For example, Wang and Shi ${ }^{[5]}$ show that the percentage of $\mathrm{CO}_{2}$ emissions caused by China's household consumption and total $\mathrm{CO}_{2}$ emissions increased from $19 \%$ in 1995 to $30 \%$ in 2004 . Liu et al. ${ }^{[6]}$ show that $\mathrm{CO}_{2}$ emission from household consumption accounted for more than $40 \%$ of total carbon emissions in China in 1992-2007. So there will have a larger carbon reduction potential in the field of resident's life, it is also one of the most important field of carbon emission reduction in our country. Ji et al. ${ }^{[7]}$ show that total and per capita carbon emissions in urban and rural areas increased rapidly in the past ten years (2003-2012). Even though it is difficult to promote energy conservation and emissions reduction technology, products and concept in the field of household energy use as a result of residents' energy consumption and its carbon emissions is dispersed.

Direct energy consumption is the main source of household energy-related carbon emissions. The recent researches are mostly to measure and evaluate direct and indirect household energy-related carbon emissions ${ }^{[4,8-12]}$, but quantitative study on the influence factors of direct household energy carbon emissions is not enough. There are insufficient in existed quantitative study on the influence factors of direct household energy carbon emissions. Chen et al. ${ }^{[13]}$ and Zhong et al. ${ }^{[14]}$ have decomposed residents household energy-related carbon emissions in China into population (or family)scale, per capita(or per household) income level, energy intensity, energy structure, energy carbon emission coefficient by LMDI (Logarithmic Mean Divisia Index) method. However, it is questionable in these two papers that they take the ratio of the energy consumption and the total income as "energy intensity" of household department, and have the same mean with "energy intensity" of productive department, which is the ratio of the energy consumption and Gross Domestic Product (GDP) of productive department. Wang ${ }^{[15]}$ decomposed residents' household energy-related carbon emissions in china into

\footnotetext{
*Corresponding author: wangwj@ms.giec.ac.cn
} 
carbon emission coefficient, energy structure, energy prices, energy consumption expenditure proportion, the per capita consumption expenditure level, urban and rural structure of population, and population size. In this paper, it is ok that they take carbon emissions coefficient of the coal, oil, natural gas as constant, but it is inappropriate that regard carbon emissions coefficient of electric power as a constant, too, because the carbon emissions coefficient of electric power will change with the change of structure of electricity generation and fuel structure of power generation in the upstream.

Though the influence factors of China household energy-related carbon emissions are decomposed more and more detailed in above researches, there are still main insufficient points that the existing research is still stay at the national scale. There are obvious regional differences in regional economic development level, resident's consumption patterns and consumption habits in China. So it is needed to carry out related research on factor decomposition of household energy-related carbon emission in regional level, to explore the influence factors with regional characteristics.

In view of this, Guangdong province, which has the greater population size, fastest grow speed of industrialization and urbanization in south China, is selected as research object in this study, and the decomposition quantitative model of household energyrelated carbon emission in Guangdong is established based on Kaya identity. The results can not only guide residents to have low carbon life with reasonable consumption patterns in Guangdong province, but also have a certain reference to the low carbon economy development of other areas in China, and provide decision-making basis for the relevant government departments to make scientific and effective carbon emission reduction measures in household department.

\section{Methodology and data sources}

\subsection{Calculation of household energy-related carbon emission}

$$
C=\sum_{i} \sum_{j} C_{i j}=\sum_{i} \sum_{j} E_{i j} \times f_{i}
$$

Where, $C$ is carbon emissions from household energy consumption, $i$ is the type of energy, $i=1,2,3,4$, represents coal, oil, gas and power, respectively, $j$ is the type of resident, $j=1,2$, represents urban resident and rural resident, respectively, $E_{i j}$ represent consumption of energy $i$ by $j$ resident, and $f_{j}$ is carbon emission coefficient of energy $i$. electric power occupies a larger proportion in the total household energy consumption, so this article will incorporate the electric power production carbon emissions into resident's consumption carbon emissions according to electric power consumption of residents, that is, electric power will be directly included in the household energy consumption as carbon emission energy.

It is difficult to distinguish the type of electric power in household consumption in detailed, this article will use average carbon emission coefficients $\left(\mathrm{Coe}_{\text {aver }}\right)$ of electric power generation to calculate carbon emissions caused by resident's consumption. Coefficients can be calculated by formula (2).

$$
\mathrm{Coe}_{\text {aver }}=\frac{\sum_{k} \sum_{i} E_{i k} \times f_{i k}}{T_{e}}=\frac{\sum_{i} E_{i} \times f_{i}}{T_{e}}
$$

Where, $T_{e}$ is total amount of electric power generation, $i$ is the type of energy, $k$ is the type of electric power generation. At present, the type of electric power generation of Guangdong are thermal power, hydropower, wind power and nuclear power, etc .Thermal power is the source of carbon emissions, hydropower, wind power, nuclear power and other basic belong to zero carbon emission energy. So the electric power carbon emission only means carbon emission of thermal power generation in the formula (2), so $k=1$. Carbon emission coefficients of coal, oil, gas are $0.7476 \mathrm{tC} / \mathrm{tSCE}$ (ton carbon/ton standard coal equivalent), $0.5825 \mathrm{tC} / \mathrm{tSCE}, 0.4435 \mathrm{tC} / \mathrm{tSCE}$, respectively. Average carbon emission coefficients of electric power generation can be seen from Table 1.

Table 1. Average carbon emission coefficients of electric power generation in 1995-2011

\begin{tabular}{|l|c|c|c|c|c|}
\hline & Coe $_{\text {aver }}$ & & Coe $_{\text {aver }}$ & & Coe $_{\text {aver }}$ \\
\hline 1995 & 1.53 & 2003 & 1.28 & 2011 & 1.46 \\
\hline 1996 & 1.56 & 2004 & 1.55 & 2012 & 1.37 \\
\hline 1997 & 1.44 & 2005 & 1.56 & 2013 & 1.37 \\
\hline 1998 & 1.49 & 2006 & 1.52 & 2014 & 1.27 \\
\hline 1999 & 1.54 & 2007 & 1.53 & 2015 & 1.23 \\
\hline 2000 & 1.52 & 2008 & 1.48 & 2016 & 1.17 \\
\hline 2001 & 1.53 & 2009 & 1.43 & & \\
\hline 2002 & 1.53 & 2010 & 1.44 & & \\
\hline
\end{tabular}

Note: the unit of Coe aver is ton carbon/ton standard coal equivalent ( $\mathrm{tC} / \mathrm{tSCE})$

\subsection{Decomposition model of household energy- related carbon emission-based on kaya identity}

$C=\sum_{j} \sum_{i} \frac{C_{i j}}{E_{i j}} \times \frac{E_{i j}}{E_{j}} \times \frac{E_{j}}{P_{j}} \times \frac{P_{j}}{P} \times P=\sum_{j} \sum_{i} f_{i j} \times s_{i j} \times l_{j} \times d_{j} \times p$

Where $\mathrm{C}, i, j$ have the same mean with that in formula (1), $\mathrm{C}_{i j}$ represent carbon emission of energy $i$ by $j$ resident. $E_{i j}$ represent consumption of energy $i$ by $j$ resident. $\mathrm{P}_{j}$ represent population size of $j$ resident. $\mathrm{P}$ is total population. $f_{i j}$ represent carbon emission coefficient of energy. $s_{i j}$ is the proportion of $i$ energy in the energy consumption of $j$ resident, i.e. energy structure. $l_{j}$ is the energy consumption of per capita of $j$ residents, i.e. energy use level. $d_{j}$ is the proportion of $j$ resident in total population, i.e. urban and rural structure of population. $p$ is total population size.

The LMDI (Logarithmic Mean Divisia Index) method is widely used in decomposition of influence factors of energy-related carbon emission for that it can satisfy the requirement of factor reversible and the residual item eliminated, which makes the model more convincing [16]. So LMDI method is also used in this article. 
Take the year 1995 as the base time, set the total carbon emission in base time is $\mathrm{C}_{0}$ and in $\mathrm{T}$ time is $\mathrm{C}_{\mathrm{T}}$, $\triangle \mathrm{C}_{\text {tot }}$ is the change of $\mathrm{T}$ time to base time, there is,

$$
\Delta C_{\text {tot }}=C_{T}-C_{0}
$$

We decompose $\Delta \mathrm{C}_{\text {tot }}$ into five different factors, the expression for the contribution values of the five decomposed factors of energy-related carbon emissions from the household sector are as follows.

$$
\begin{aligned}
\Delta C_{f_{i j}} & =\sum_{i} \sum_{j} \alpha \ln \frac{F^{T}{ }_{i j}}{F^{0}{ }_{i j}} \\
\Delta C_{s_{i j}} & =\sum_{i} \sum_{j} \alpha \ln \frac{S^{T}{ }_{i j}}{S^{0}{ }_{i j}} \\
\Delta C_{l_{j}} & =\sum_{i} \sum_{j} \alpha \ln \frac{L^{T}{ }_{j}}{L^{0}{ }_{j}} \\
\Delta C_{d_{j}} & =\sum_{i} \sum_{j} \alpha \ln \frac{D^{T}{ }_{j}}{D^{0}{ }_{j}} \\
\Delta C_{p} & =\sum_{i} \sum_{j} \alpha \ln \frac{P^{T}}{P^{0}} \\
\text { Where, } & \alpha=\frac{C^{T}{ }_{i j}-C^{0}{ }_{i j}}{\ln C^{T}{ }_{i j}-\ln C^{0}{ }_{i j}}, \text { and } \Delta \mathrm{C}_{f i j}, \Delta \mathrm{C}_{s i j}, \Delta \mathrm{C}_{l j}, \Delta \mathrm{C}_{d j},
\end{aligned}
$$

$\Delta \mathrm{C}_{p}$ are the contribution values of each factor to total carbon emission by the changes of carbon emission coefficient, energy structure, energy use level, urban and rural structure of population, population size, respectively. Total change of carbon emission can be expressed as below.

$$
\Delta C_{\text {tot }}=C_{T}-C_{0}=\Delta C_{f_{i j}}+\Delta C_{s_{i j}}+\Delta C_{l_{j}}+\Delta C_{d_{j}}+\Delta C_{p}
$$

\subsection{Data sources and processing}

The energy data used in this paper are quoted from Energy Balance Sheet of Guangdong Province in the China Energy Statistical Yearbook (1996-2017). Other data come from the Statistical Yearbook of Guangdong Province (1996-2017) and Statistical Yearbook of china (1996-2017). The year 1995 is set as baseline year in LMDI method in this article.

\section{Results and discussion}

\subsection{Analysis on total household energy-related carbon emission}

The estimated results show that the total household energy-related carbon emissions in Guangdong province increase from 5.72 million ton in 1995 to 23.83 million ton in 2015 , and decline slightly to 20.75 million ton in 2016. It accounts for about $16 \%$ of the total energyrelated carbon emission in Guangdong.

See from urban and rural structure of carbon emission (Fig.1), carbon emission from urban households increase from 3.79 million ton in 1995 to 13.43 million ton in 2016, it accounts for about $65 \%$ of the total household energy-related carbon emission, it is far greater than carbon emission from rural households.
Table 2. Total household energy-related carbon emission during 1995-5016

\begin{tabular}{|c|c|c|c|}
\hline & Urban & Rural & Total \\
\hline 1995 & 3.79 & 1.93 & 5.72 \\
\hline 1996 & 4.10 & 2.23 & 6.33 \\
\hline 1997 & 4.05 & 2.20 & 6.25 \\
\hline 1998 & 4.30 & 2.34 & 6.64 \\
\hline 1999 & 4.49 & 2.64 & 7.13 \\
\hline 2000 & 4.78 & 2.75 & 7.53 \\
\hline 2001 & 5.17 & 3.02 & 8.18 \\
\hline 2002 & 5.31 & 3.11 & 8.42 \\
\hline 2003 & 5.54 & 2.98 & 8.52 \\
\hline 2004 & 6.54 & 3.58 & 10.13 \\
\hline 2005 & 8.22 & 3.98 & 12.20 \\
\hline 2006 & 8.65 & 4.25 & 12.90 \\
\hline 2007 & 9.81 & 4.73 & 14.54 \\
\hline 2008 & 10.11 & 5.43 & 15.54 \\
\hline 2009 & 10.72 & 5.83 & 16.55 \\
\hline 2010 & 11.42 & 6.12 & 17.54 \\
\hline 2011 & 13.59 & 7.56 & 21.15 \\
\hline 2012 & 12.49 & 7.66 & 20.15 \\
\hline 2013 & 13.57 & 7.52 & 21.09 \\
\hline 2014 & 14.25 & 7.71 & 21.97 \\
\hline 2015 & 15.21 & 8.62 & 23.83 \\
\hline 2016 & 13.43 & 7.33 & 20.75 \\
\hline
\end{tabular}

Note: the unit is million ton carbon

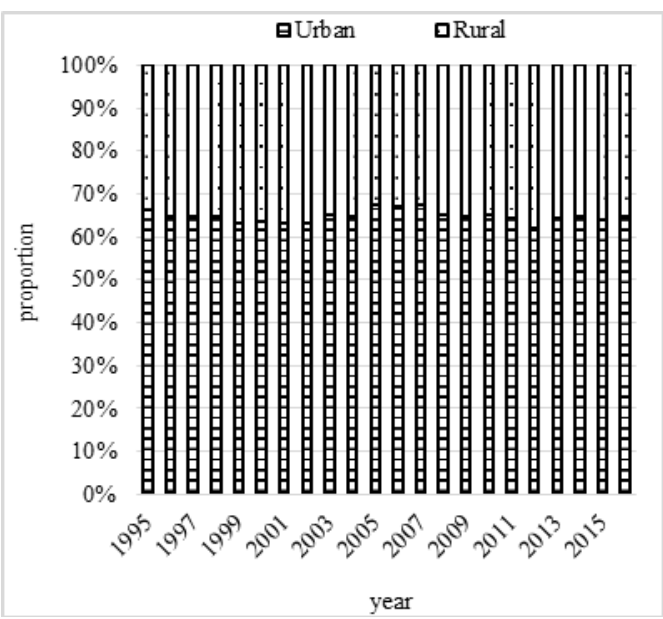

Fig.1. Urban and rural structure of household energy-related carbon emission during the year 1996-2016

See from energy structure of carbon emission (Fig.2), oil and electric power consumption are main source of carbon emission, the proportion of sum carbon emission of oil and electric power in household energy-related carbon emissions increased from $72.1 \%$ in 1995 to $92.5 \%$ in 2016 . Among them, the proportion of electric power carbon emissions increase year by year, mainly because the proportion of coal in thermal power generation increase from $66.8 \%$ in 1995 to $94.8 \%$ in 2013 and decline to $90 \%$ in 2016 slowly (Fig.3) . Thus it can be seen that electric power generation of Guangdong is still in the direction of high carbon emissions, energy structure of electric power generation has been optimized from 2014. Even so, electric power 
consumption is still the first emitters in the household energy-related carbon emissions.

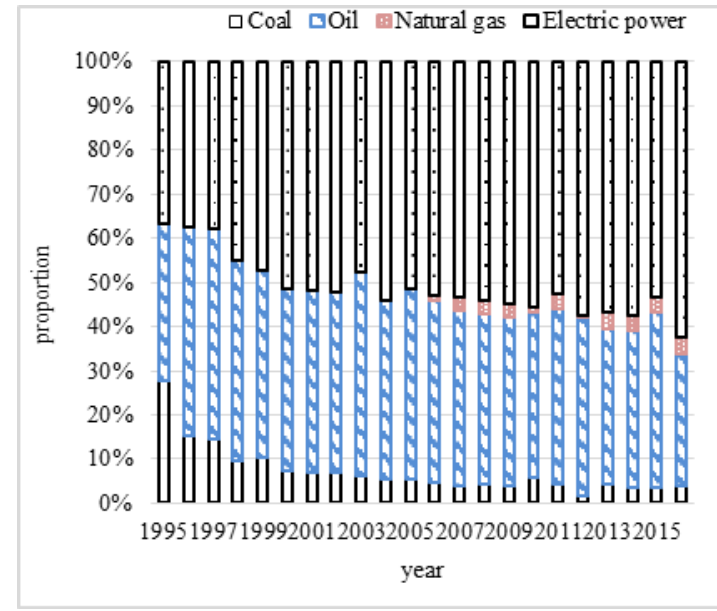

Fig.2. Energy structure of household energy-related carbon emission during the year 1996-2016

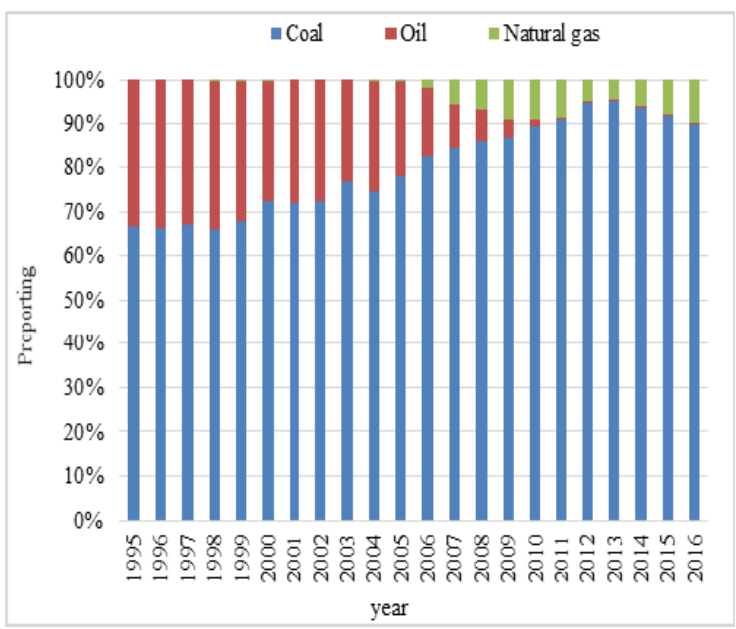

Fig.3. Energy structure of thermal power generation during the year 1996-2016

\subsection{Decomposition analysis on influence factor of household energy-related carbon emission}

See from the results of decomposition, we draw two conclusions: (1) Energy structure (except in 1996-1997), energy use level, urban and rural structure of population, population size have promoting effect on household energy-related carbon emissions (Fig.4). Among them, population size has the largest contribution to the increase of carbon emission in 1996-2004, which is the first promoting factor to household energy-related carbon emission, followed by energy use level. But in 2005-2016, energy use level effect exceeds population size and becomes the first promoting factor. Carbon emission coefficient shows reduction effect, which is the first inhibiting factor to energy-related carbon emission. (2) See from the time series change of contribution values of various decomposition factors, there is larger fluctuation in 1997 and 2003 for most of decomposition factors. That is because, in 1997, the Asian Financial
Crisis originated in Thailand is undoubtedly a fatal blow to Guangdong where economic development mainly relies on exports and investment. Meanwhile, some deep-seated contradictions formed in the rapid development of Guangdong since reform and opening up began to surface gradually during this period. Both reasons lead to economic growth rate of Guangdong declining year by year, until 2000, it began to rise again. This shows that economic shocks have impact on the residents' household consumption through it influence on various decomposition factors. And in 2003, Severe Acute Respiratory Syndrome (SARS) started in shunde district of Foshan city, Guangdong province, and spread to the whole country quickly, this caused a nationwide panic and affected the people's life seriously, especially in Guangdong province.

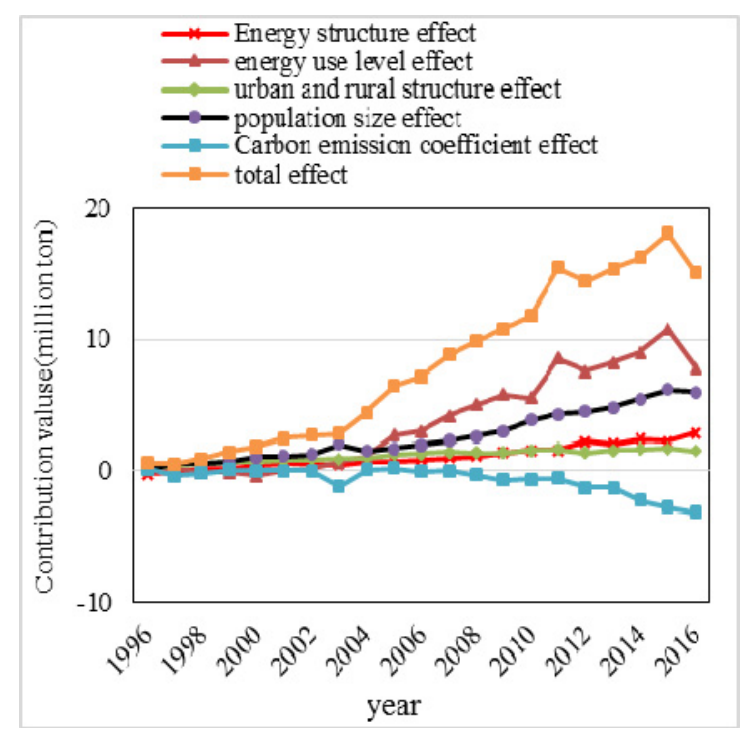

Fig.4. Change trends of contribution values of five influence factors during the year 1996-2016

\section{(1) Carbon emission coefficient effect}

Carbon emission coefficient shows reduction effect during the research period in most of the time. The contribution of carbon emissions coefficient main comes from the change of the average carbon emission coefficients of power generation. During the research period, average carbon emission coefficients of power generation shows fluctuating trend during the year19952005, and shows steady downward trend during the year 2006-2016(Fig.5). The contribution values also show irregular change trend in 1996 to 2005 (Fig.6), and show steady downward trend during the year 2006-2016. This indicates that reduction effect of carbon emission coefficient become stronger and stronger since 2006 . 


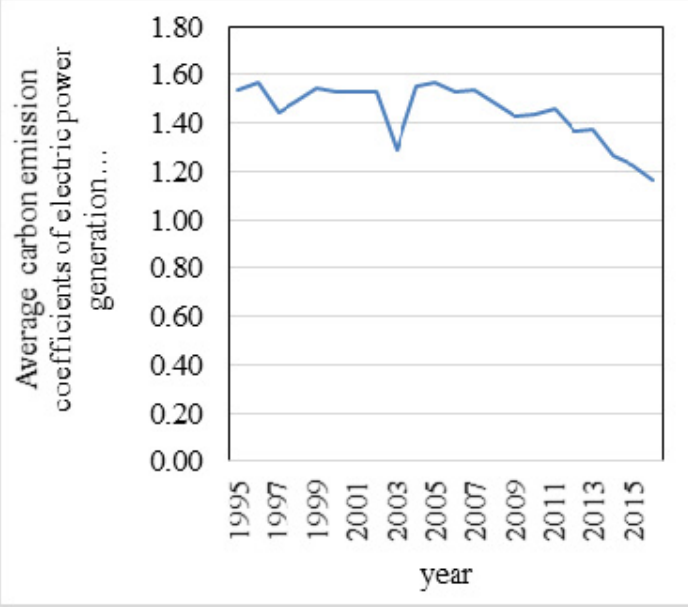

Fig.5. Change trends of average carbon emission coefficients during the year 1996-2016

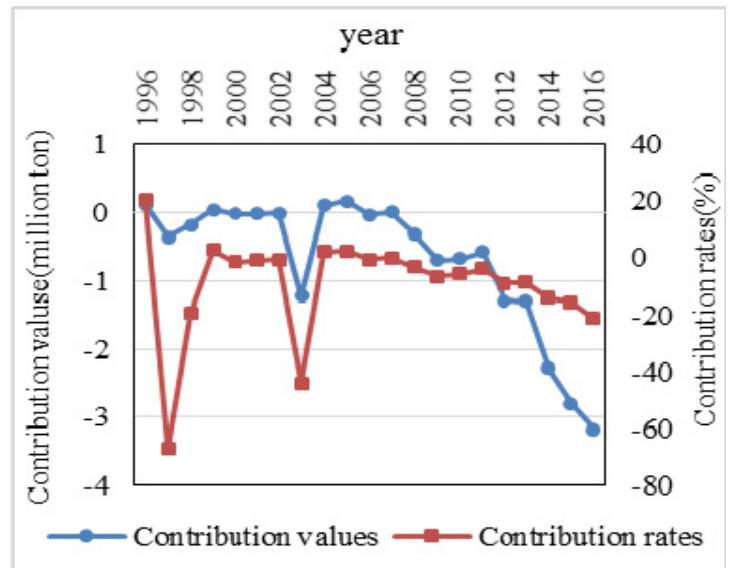

Fig.6. Change trends of contribution values and contribution rates of average carbon emission coefficients during the year 1996-2016

\section{(2)Energy structure effect}

Energy structure show reduction effect in 1996-1997, and turn to carbon emissions increase effect in 19982016(Fig.7). The classification of household energy in this article is not the same as before research, so this conclusion does not agree with previous research results. Previous research results show that the energy structure show carbon emissions reduction effect. This article treats electricity as direct source of carbon emissions, the power becomes high carbon energy as coal. This leads to high proportion of high carbon energy in household energy consumption (Fig.2). The change of energy structure did not have carbon reduction effect, but make carbon emissions increase gradually, the contribution value is 2.87 million ton in 2016 .

See from contribution rates of energy structure to total increment of carbon emission (Fig.7), the rate increase from $12.6 \%$ in 1998 to $24.6 \%$ in 2000 , and decrease to $10.9 \%$ in 2005 year by year, after then, the contribution rates fluctuate at $13 \%$. This indicates that increase effect of energy structure is weakening year by year during 2000-2005, then stay at a stable level during the year 2005-2016. So household energy structure should be further optimized and adjusted in Guangdong province. For example, the government should guide

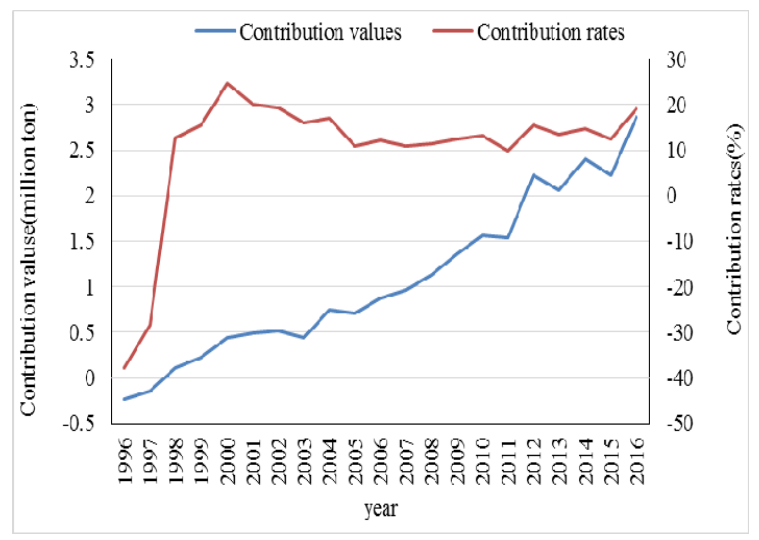

Fig.7. Change trends of contribution values and contribution rates of energy structure to carbon emission during the year 1996-2016

residents for green travel, on the one hand, government should encourage people to take public transportation, on the other hand, they should improve the supply ratio of diesel fuel and gasoline fuel with low carbon and low sulfur, reduce carbon emissions of the whole transportation field. In terms of electric power consumption, relevant departments should on the one hand, enhance the adjustment intensity of the energy structure of thermal power generate, increase the proportion of clean energy, such as wind, hydro and nuclear power, to reduce the carbon emission of unit electricity. On the other hand, take necessary measures to stop residents' bad habit of waste on the electricity, advocate economical living concept to save electricity. Finally made the effect of energy structure to carbon emissions could turn to reduction from increase.

\section{(3) Energy use level effect}

Energy use level show reduction effect during the year 1998-2000, and show increase effect during the year 1996-1997 and during the year 2001-2016 (Fig.8).

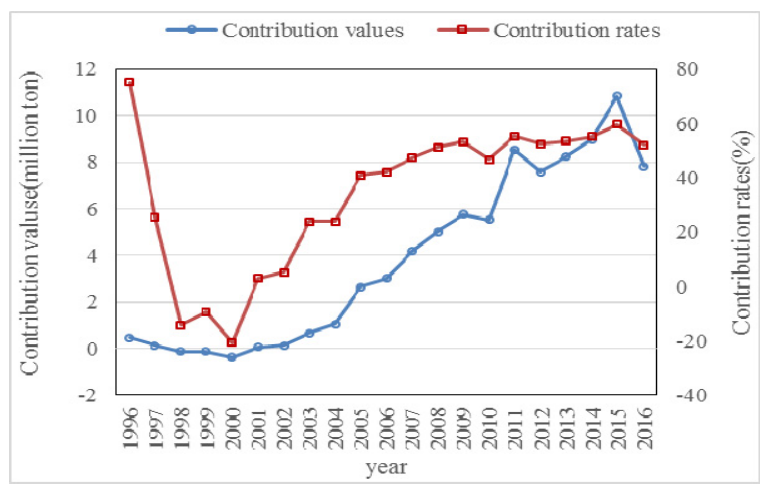

Fig.8. Change trends of contribution values and contribution rates of energy use level to carbon emission during the year 1996-2016

Its contribution values decrease from 0.46 million ton in 1996 to -0.37 million ton in 2000 , and then increase from 0.07 million ton in the year 2001 to 10.83 million ton in the year 2015 , and decline slightly to 7.82 million 
ton in the year 2016. Its contribution rates decrease from $75 \%$ in the year 1996 to $-20.7 \%$ in the year 2000 , and then increase from $2.95 \%$ in the year 2001 to 59.8 in the year 2015 , and decline slightly to $52 \%$ in the year 2016 .

(4) Urban and rural structure of population effect

Urban and rural structure show increase effect during the year 1996-2016.Increment of carbon emission caused by the change of urban and rural structure of population increase from 0.19 million ton in 1996 to 1.53 million ton in 2016 , its contribution rate decline from $70.2 \%$ in 1997 to $10.2 \%$ in 2016 year by year (Fig.9). It can be seen that the impact of the change of urban and rural structure of population on household energy carbon emissions should not be ignored. As a result of the urban residents energy use level is higher than that of rural residents, the improvement of urbanization level, that represented by the change of urban and rural structure of population, overall promote residents household energy carbon emissions of Guangdong growth in a certain extent. The contribution rate of the change of urban and rural structure of population on carbon emission decrease year by year, which indicates that with the improvement of urbanization level, the gathered of urban population bring scale economy for the use of public goods and coupled with changes in life style and technology diffusion, the impact intensity of the change of urban and rural structure of population on household energy carbon emissions become weaker.

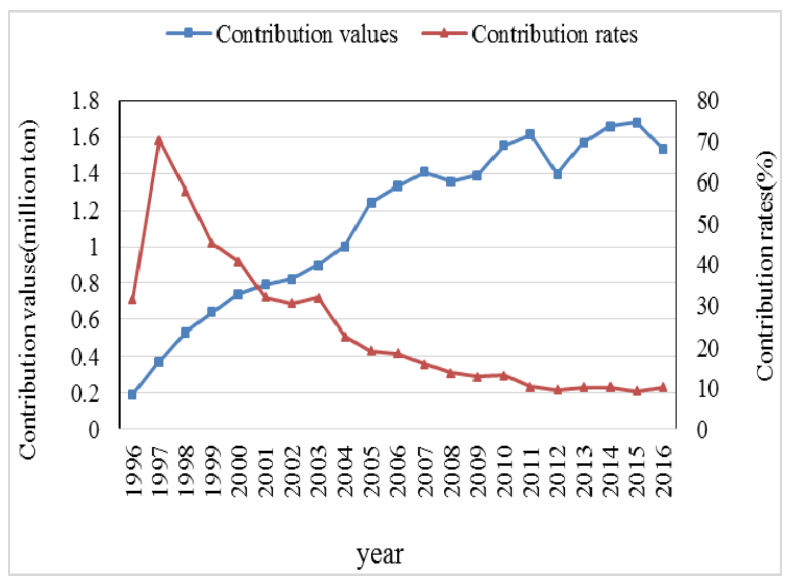

Fig.9. Contribution values and contribution rates of urban and rural structure of population during the year 1996-2016

\section{(5) Population size}

The change of population size overall show increase effect on carbon emission(Fig.10), the increment increase from 0.07 million ton in 1996 to 5.98 million ton in 2016, its contribution rate increase from $10.8 \%$ in 1996 to $99.4 \%$ in 1997 , decline to $26.3 \%$ in 2005 , then increase to $39.8 \%$ in 2016 slowly.

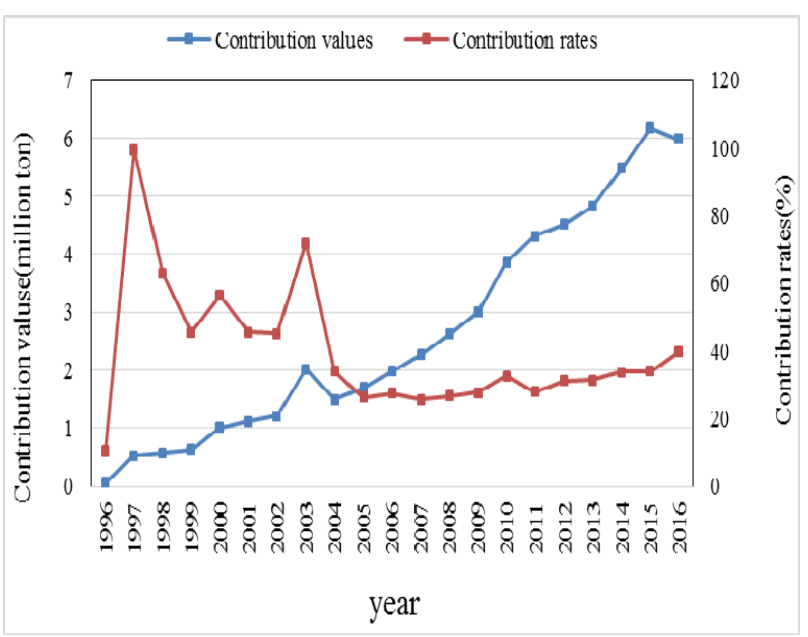

Fig.10. Contribution values and contribution rates of population size during the year 1996-2016

\section{Conclusions and policy implication}

\subsection{Conclusions}

Based on the extended Kaya identity, the decomposition quantitative model of household energy-related carbon emission in Guangdong is established with the Logarithmic Mean Divisia Index (LMDI) method, influence factors of household energy-related carbon emission are decomposed into five factors. Main results show that total household energy-related carbon emission in Guangdong province show increase trend from 1995 to 2016. Oil and power consumption are two main sources of carbon emission. See from urban and rural structure of carbon emission, carbon emission from urban residents account for about $65 \%$ to the total household energy-related carbon emissions, which is greater than rural residents.

From the results of decomposition analyze, we draw the conclusions that energy structure (except in 19961997), energy use level, urban and rural structure of population, population size have promoting effect on household energy-related carbon emissions. Among them, population size is the first promoting factor to household energy-related carbon emission in 1996-2004. Energy use level become the first promoting factor in 2005-2016. Carbon emission coefficient show reduction effect, which is the first inhibiting factor to energyrelated carbon emission.

\subsection{Policy implication and suggestions}

There are two most effective measures to realize household energy-related carbon emission reduction according to analysis results.

(1) Adjusting household energy structure, improve the efficiency of power utilization

Electric power consumption is main source of household carbon emission which proportion increased from $36.9 \%$ in 1995 to $621.4 \%$ in 2016 . Electric carbon emission mainly come from thermal power generation, 
so it will be an effective means to reduce household carbon emissions by strengthen the adjustment on the energy structure of thermal power generation, increase the proportion of clean energy, such as wind, hydro and nuclear power, reduce the carbon emission of unit electricity. On the other hand, it also will be an effective means to reduce household carbon emissions by installing household energy intelligent system, use high tech technology to save electricity. Finally, what we hoped to get is the effect of energy structure on carbon emissions could turn to decreases from increase by these measures.

(2)Optimizing urban and rural structure of population

With the improvement of urbanization level, the gathered of urban population bring scale economy for the use of public goods, and coupled with changes in life style and diffuse of technology, the impact intensity of the change of urban and rural structure of population on household energy carbon emissions is more and more weak, therefore, government should further optimize urban and rural structure of population, to promote the role of economies scale show up as soon as possible.

\section{Acknowledgments}

The authors gratefully acknowledge the financial support of the low-carbon development special fund project of Guangdong province (Grant No.y609qb1001).

\section{References}

1. K.Y.Wu, Xu.Guo, W.X.Wang, H.Zhang. Res.and Env. Y.B 22,535-543 (2013)

2. S.Pachauri, D.Spreng. Ene.Pol 30,511-523 (2002)

3. S.Bin, D.latabadi. Ene.Pol.33,197-208(2005).

4. A.Druckman,T.Jackson.Eco.Eco68, 2066-2077 (2009)

5. Y.Wang, M.J.Chi.Jou.Pop.Res.Env7,11-19 (2009)

6. L.C.Liu,G.Wu,J.N.Wang,Y.M.Wei.Jou.C.P.19,175 4-1762 (2011)

7. Z.Y.Ji, X.F.Lai, L.J.Jia. Chi.Pop.,R.E.26,6472(2016)

8. J.Munksgaard, K.A.Pedersen, M.Wien. E. E. 22,423-440 (2000)

9. H.Hens, G.Verbeeck, B.Verdonck. E.B.33,275-281 (2001)

10. R.Saidur,H.H.Masjuki,M.Y.Jamaluddin,S.Ahmed.E .P.35,1648-1657(2007)

11. A.C.Kerkhof,R.M.J.Benders,H.C.Moll.E.P.37,1509 -1517(2009)

12. J.P.Zha, F.F.Tang, H.Fu. Jour. S.F.E.U.32,9-15(2010)

13. S.Y.Chen, R.C.Wu.S.E.R.4,10-23 (2011)

14. Y.Y.Zhong, W.Z.Zhong.J.Fi.E.38,123-133 (2012)

15. Z.Wang. University of Science and Technology of China. (2012)

16. B.W.Ang. E.P.32,1131-1139(2004) 